\title{
O JORNAL DORT'UGAL DE'MOCRÍTICO: Demandas do literário em meio à proposta política
}

\begin{abstract}
Não sei se algum dia se escreverá a história (que vários tenderão a escrever diversamente) da actividade dos oposicionistas no Brasil, capítulo de alguma importância na longa cadeia de acções que culminou no 25 de Abril.
\end{abstract}

(Sena, 1988:227)

Como já indicia a epígrafe, tratarei aqui de uma das várias prefigurações da "Revolução dos Cravos": do jornal Portugal Democrático, editado em São Paulo de 1956 a 1975 e congregador de brilhante grupo de exilados portugueses no Brasil, que, nada ortodoxamente, se destacou como assumida forma de ação anti-salazarista fora de Portugal, praticando vários modos de sociabilidade. E, dentre a variedade de enfoques que a leitura de suas páginas permite, sublinharei a presença constante da literatura uma das portas abertas para o diálogo fértil com intelectuais brasileiros.

Para tratar deste jornal cuja importância pretendo justificar, conviria primeiro apresentá-lo, pois não são muitas as pessoas que dele têm notícia, embora seja incontornável inseri-lo naquela literatura de oposição produzida durante os anos de ditadura salazarista, que, consensualmente, constitui fonte documental da maior importância para avaliação do período. Contudo, os estudos nesse âmbito, quer em Portugal, quer no Brasil são escassos.

Assim sendo, começaria por assinalar que este jornal, cujo primeiro número vem à luz com a data de 07 de julho de 1956, fundado e mantido por portugueses exilados por motivos políticos, não é um fenômeno isolado no Brasil, em São Paulo. Em muitas de suas próprias páginas encontramos referências a órgãos congêneres existentes em outros países, como Comitếs ou Associações oposicionistas, de que o Comitê 
dos Portugueses Democratas do Canadá e a Agrupação de Portugueses Democratas do Uruguai servem de exemplo. Além do intercâmbio mantido com tais entidades, o expediente do jornal menciona ainda correspondentes da França, Venezuela, Argentina e Checoslováquia, indiciando uma rede articulada de circulação "clandestina" de informações.

Desde logo o Portugal Democrático contou com um corpo de colaboradores de alto nível, reunidos em torno da figura tutelar de João Sarmento Pimentel - exilado da primeira hora em que Salazar galga o poder e que na capital paulista veio a tornar-se o Presidente do Centro Republicano Português. Certamente foi pelas mãos de seus amigos Adolfo Casais Monteiro e Fernando Lemos - veteranos colaboradores - que Jorge de Sena foi levado ao jornal, passando a conviver com outros nomes ao tempo igualmente respeitáveis como Carlos Maria de Araújo, Paulo de Castro, Joaquim Barradas de Carvalho, Vítor Ramos, Miguel Tavares Rodrigues... Eventualmente, portugueses que não adotaram o exílio brasileiro, como António José Saraiva, têm aí textos seus publicados. Eventualmente, renomados escritores brasileiros, como Manuel Bandeira, Raquel de Queirós, Gustavo Corção, Álvaro Lins, Rubem Braga, Fernando Sabino, Murilo Mendes, assinaram artigos em suas páginas. A simples enumeração destes nomes, seguidores das mais variadas tendências político-ideológicas, bem atesta o quanto a solidariedade dos intelectuais brasileiros para com seus oprimidos confrades portugueses suplanta diferenças. Solidariedade que se exprime claramente no repúdio, em uníssono, à política obscurantista de Salazar em relação à cultura e que se emblematiza num título como "Réquiem para o dono de Portugal", de um longo artigo de Fernando Sabino.

Foram os meus estudos sobre Jorge de Sena, particularmente sobre a assombrosa produção nos seus anos "brasileiros" e a enorme interação com os intelectuais da época, que me conduziram à descoberta do Portugal Democrático. A adesão de Jorge de Sena ao periódico é, antes de mais, a adesão a um grupo intelectual que comunga das mesmas convicções políticas. Assim, por um lado, pode ele repetir no Brasil o convívio fértil que promovia em Lisboa, nos cafés primeiro, em sua casa depois; por outro, ao poder exteriorizar suas idéias sem amarras, como que faz ampliar em coerência a sua personalidade. Recorda Mécia de Sena, sua viúva (Stegagno Picchio, 1983: 1422):

Inicia uma longa colaboração [...] no Portugal Democrático, órgão da oposição portuguesa a cujo conselho de redacção pertence por três anos, e onde, só neste lapso de tempo, há mais de trinta entradas suas. E é no Brasil que exerce a sua mais intensa 
actividade política, já que, abertamente, a não pudera nunca exercer em Portugal, sem perigos que não podia correr com tão numerosa família.

Na lista dos 37 textos que Sena publicou no Portugal Democrático, entre o número 30 (novembro de 1959) e o número 65 (outubro de 1963), contam-se 25 textos assinados, 09 anônimos, 02 textos coletivos, e 01 com pseudônimo. Dos anônimos, 08 são editoriais, que, por expressarem o posicionamento do próprio jornal, é consuetudinário não levarem assinatura. O remanescente apenas anuncia o "triplo poema" de Fernando Pessoa contra Salazar, que tinha sido publicado no mês anterior no Estado de São Paulo". Os textos coletivos são a "Carta-protesto sobre a morte do Capitão Almeida Santos" (ñ 36, de maio de 1960) e o "Comunicado do Comité dos Intelectuais" (n ${ }^{\circ}$ 58, de março de 1962). Sob o pseudônimo altamente irônico de "Cândido Alves", assina sua quarta participação no jornal, cujo título bem justifica essa estratégia - "Eleições em Portugal" (n⿳3 31, dezembro de 1959).

Em tempo, diga-se que outros dos colaboradores também recorreram ao anonimato ou ao pseudônimo. Eduardo Lourenço declarou de público, num Colóquio que organizei no Rio de Janeiro em $1998^{2}$, ter escrito para o Portugal Democrático sem que lá aparecesse seu nome, pois, palavras suas, "pretendia voltar a Portugal"... Não teria sido infundada a prudência do eminente pensador: há no dossier de Jorge de Sena guardado nos arquivos da PIDE cópias de várias de suas colaborações no Portugal Democrático as quais, de certeza, teriam pesado para que, "a bem da Pátria”, o Gabinete do Ultramar emitisse contra ele um "Pedido de Captura" datado de janeiro de 1962, bem como, em julho do mesmo ano, fosse assinada a "interdição da entrada em território nacional para este indivíduo” (somente suspensa em 1968).

O tom contundente de suas colaborações justificaria a medida. À guisa de exemplo, até bastante sóbrio, é o comentário analítico à fuga de Agostinho Neto, depois de ter ele sido posto em liberdade vigiada. Foi estampado no número 63, de agosto de 1962:

\section{AGOSTINHO NETO}

O presidente do Movimento de Libertação de Angola, o escritor Agostinho Neto fugiu de Portugal, e vai a caminho de Inglaterra. Salazar, que o conservava preso, ultimamente pusera-o em residência vigiada. Esta pretensa benevolência do ditador por certo se destinava a dois fins: mostrar à opinião pública mundial que inimigos políticos 
de alta importância são tratados com consideração, e observar quem, na liberdade relativa do líder angolano, se aproximava dele. No fim de contas, em residência vigiada é como toda a gente vive em Portugal, sem que as potências aliadas de Salazar se preocupem muito com isso. E se a Agostinho Neto era dado, ostensivamente o mesmo tratamento, isso apenas se devia ao fato de Angola se ter tornado (como o próprio Portugal ainda não) uma questão mundial. A fuga do chefe angolano não estava, por certo, nos planos do ditador. Livre na Inglaterra - se a Inglaterra o acolher - ele constituirá um sério problema para Salazar, a menos que a velha raposa de Santa Comba não esteja pensando em servir-se desse problema para melhor negociar com os Estados Unidos, afastando-se mais da Inglaterra. De qualquer modo, Portugal Democrático congratula-se com a liberdade plena que Agostinho Neto terá conquistado, após tantas perseguições. O governo de Lisboa apresenta internacionalmente, como óbice à independência de Angola, a falta de líderes que possam governar. Presos é que eles nunca governarão... E soltos, podendo falar ao mundo, serão sempre um passo decisivo para a queda da oligarquia sinistra que governa Portugal.

A função precípua do periódico, de tiragem mensal, além de congregar intelectuais portugueses unidos pelo mesmo ideário de protesto e denúncia em relação aos desmandos salazarista, seria manter os, de alguma forma, "exilados" a par do que em Portugal se passava, sobretudo no sentido de uma ação oposicionista. As notícias, sempre acompanhadas de comentários críticos, visavam, obviamente, a direcionar o leitor a uma atitude de repúdio à ditadura, ao procurar despertar-lhe a consciência para as "sutilezas" da censura e repressão lá praticadas. Outro pequeno exemplo, no noticiário da página 2 do número 40, de setembro/1960:

\section{"O CASO DO 12 DE MARÇO”}

Em 25 de julho terminou, desta vez no Tribunal Militar de Santa Clara, o julgamento dos militares e civis acusados de estarem implicados numa tentativa revolucionária que devia ter eclodido na noite de 11 para 12 de março de 1959. [Segue-se a enumeração de nomes e penas]. Todos os acusados foram condenados à suspensão de direitos políticos por três anos. Aos majores Pastor Fernandes e Clodomiro Alvarenga e ao capitão Carlos Vilhena, atendendo ao seu "bom comportamento moral" (que significará isto, em termos jurídicos?) foi concedida a suspensão da pena para três anos. [grifos meus]

A propósito desse golpe frustrado - também conhecido como a "Conspiração da Sé" - vale ainda recordar outro texto de Jorge de Sena: aquele editorial tecido em torno do cadáver do Capitão Almeida Santos ${ }^{3}$, um dos líderes do "12 de Março" 
encontrado na praia do Guincho, caso que também forneceu o mote a José Cardoso Pires para a escrita do seu Balada da Praia dos Cães. Foi publicado no número 35, de abril de 1960 .

\section{OS DOIS CADÁVERES}

Noticiaram os jornais a 2 de abril, em telegrama da AFP, que "as investigações para identificação de um cadáver descoberto anteontem na praia do Guincho, perto de Lisboa, permitem suspeitar de que se trata do capitão Almeida Santos, um dos evadidos da prisão militar de Elvas, em Dezembro último, onde estava encarcerado por actividades políticas contra o regime". Tão sinistro, hipócrita e cobarde é o espírito da ditadura salazarista, que até o teor deste telegrama o retrata. É possível que o cadáver seja... Suspeita-se de que seja... Porquê? O cadáver está mutilado, irreconhecível, podre, como o próprio cadáver da Pátria que simboliza? Foi estrangulado, baleado, afogado, atropelado, atirado de uma janela alta, como todos os que "se" estrangularam, balearam, afogaram, atropelaram, atiraram - depois de caídos nas garras da PIDE? Fica-se na dúvida, a dúvida alimentada pela incerteza. Não há responsáveis de coisa alguma, ninguém é responsável de nada... Nada se passou - a não ser a satisfação dada ao registro civil de um óbito, um modesto óbito incerto que permite enterrar o sujeito em silêncio mais definitivo que uma desaparição inexplicável.

Isto é Salazar inteiro, isto é Portugal ensangüentado e trágico, que nem sequer nos cobre de vergonha com a sua atrocidade, porque permite (suspeitar...) todas as complacências, todas as cumplicidades, todas as mesuras da diplomacia covarde e interesseira. NEM SEQUER podemos ter vergonha disto, aos olhos do mundo, porque o mundo a não tem, antes de nós, de pactuar com os crimes de Salazar.

Que cadáver submisso! Que cadáver silencioso! Quantos meses levou a percorrer a escassa largura de Portugal, desde Elvas até àquele Atlântico que é o mesmo que banha as costas do Brasil! Numa praia deserta, aparece o cadáver hipotético de um homem que foi um dos chefes militares do 12 de março. Cadáver que poderia ser o de qualquer outro da enorme quantidade de civis e militares de todas as opiniões políticas que tentaram o "12 de Março" com uma extensão e uma profundidade que o Estado Novo teme esclarecer! Fazer aparecer o seu cadáver é mostrar a sorte que poderia ser a de cada um, mas é também roubar à vítima e aos outros o galardão do martírio, do sacrifício, do escândalo nacional e mundial, a que não resistiria um governo de assassinos mais vis que a vileza, porque nem mesmo tem a ombridade de estadear a sua profissão verdadeira.

Onde está o "glorioso Exército português"? Porque o capitão Almeida Santos era um dos seus membros mais brilhantes. Onde está a consciência dos pais de família. Porque o capitão Almeida Santos era um pai de família. Onde está o povo português? Porque o capitão Almeida Santos era um português. Onde está Portugal? 
Tu, Salazar, nunca fizeste serviço militar. Nunca foste - que tenhas tido a dignidade de o confessar - pai de família. Nunca foste português, porque os portugueses sempre se vangloriaram de tudo, até dos crimes. Mas serás um cadáver, hás-de ser um cadáver, terás de ser um cadáver. Não um cadáver hipotético - como o da Pátria ensangüentada - abandonado, tão ocasionalmente, numa praia deserta. Mas um cadáver - consola-te - que não terá tempo de apodrecer, como o da Pátria em trinta anos de governo teu. Um cadáver que a terra portuguesa se recusará a comer. Um cadáver que os mares de Portugal - e todos são - se recusarão a engolir.

"PORTUGAL DEMOCRÁTICO" concita a consciência do mundo a que compare e escolha - entre o cadáver hipotético do Cap. Almeida Santos, um homem de bem que tentou honestamente salvar a sua Pátria, e o cadáver inadiável do tirano, um homem de mal que tenta cavilosamente destruí-la consigo. "PORTUGAL DEMOCRÁTICO” pergunta de uma vez para sempre ao glorioso Exército português: a qual dos cadáveres ele acha que deve honras militares.

Diretamente envolvido com os fatos que geraram a captura do Capitão - de quem obviamente se tornara próximo, ainda que nem sequer o tenha conhecido -, o autor dá vazão a todo o seu repúdio a Salazar e seus agentes. Em discurso barrocamente catártico, inflamado, eivado de anáforas, enumerações, exclamações, interrogações, constrói o articulista-corifeu uma peça demolidora da ditadura que, pelo poder excessivo que concentra, tanto se arroga o direito de silenciar e tornar escassos os seus opositores, como de calar sobre seus próprios atos. Invertendo papéis, o texto excessivo de Sena, poderoso no domínio da palavra, denuncia a fragilidade moral, a escassez de dignidade nesse outro podre reino da Dinamarca.

Valho-me deste texto de Sena, aqui tomado como paradigmático, para uma palavra sobre os traços discursivos verificados nas páginas do jornal, o que não é tarefa fácil, dadas as variações de temas e de tons que nelas se observam, porém o que a seguir afirmo poderia aplicar-se a vários artigos, de vários autores.

Jorge de Sena, em vários passos - e na trilha de Shakespeare, Calderon, e inúmeros grandes autores que o antecederam ou sucederam - externou a sua concepção do mundo como um grande teatro. É, pois, sob uma ótica teatral que Sena não só concebe a política, como nela atua, reservando para si preponderantemente o papel de uma voz múltipla, coletiva - a do coro - à qual, como se sabe, cabe comentar gestos e ações das personagens. Destarte, nesses comentários, obviamente destinados a interlocutores aptos a assumirem posições, ora predominará a reflexão analítica, apoiada em arrazoados articulantes de relações causa/efeito, ágeis em deduzir ilações e em esmiuçar sutilezas nos meandros desse território pleno de areias movediças, convidando o leitor, com forte argumentação, a manter a inteligência desperta; ora 
predominará o engenho do envolvimento arrebatado, veemente, que sabe recorrer à retórica apropriada, aos efeitos sedutores, para provocar o convencimento, a adesão emocional do leitor. Enfim, no teatro político, é difícil escapar à distinção nietzschiana entre apolíneo e dionisíaco, como, aliás, em outros teatros do mundo.

Convencer os leitores é indubitavelmente uma das principais atribuições dos editoriais jornalísticos. Tal como na parênese. E no discurso da persuasão em língua portuguesa permanecem até hoje insuperáveis os pregadores barrocos, como Vieira. Donos de uma técnica retórica herdada dos greco-latinos, mas aperfeiçoada na prática missionária e pedagógica (da qual a componente política raro estava alheada), chegaram a estabelecer o paradigma do que se convencionou definir como "método português de pregar” (MENDES, 1982). Neste, para lá dos exercícios de eloqüência que privilegiarão os procedimentos estilísticos requeridos para alcançar junto ao público o delectare, o docere e o movere - incluem-se ainda instruções posturais que mais facilmente comprovam o quanto a ação parenética valorizava o teatral. Mas teatral também será o próprio texto sermonístico que elege a interrogação como elemento supremo e condutor das argumentações que se ramificam em incontáveis agudezas, silogismos, simetrias, jogos conceptuais... A interrogação pressuporá sempre um interlocutor, do qual se deseja a atenção e sobre o qual se quer atuar; por isso condensa em si a essência do drama. Já percebe quem me lê aonde pretendo chegar... Este editorial, concebido por Jorge de Sena para denunciar um "Portugal ensangüentado e trágico" (grifo meu), atualiza habilmente a retórica da persuasão parenética, com seu vasto repertório de efeitos teatrais, com vistas a envolver inapelavelmente o leitor (há oito grandes perguntas no texto e é com um ponto de interrogação que o texto se encerra) e a conduzi-lo a uma única resposta: repúdio total ao teatro - trágico ou farsesco - que Salazar comanda.

Para quem navega pela poesia de Sena, ressoam neste artigo candente ecos do poema "Carta a meus filhos sobre os Fuzilamentos de Goya" e prenúncios do amargo poema "A Portugal" como ecos e prenúncios de muitos outros textos literários de Sena onde o pensamento político se mescla ao pensamento ético, moral, humanístico.

Voltando ao episódio do "12 de março", competirá aos historiadores apurar os fatos, rastrear os passos para a identificação do cadáver e discutir a autoria do crime, se é que crime houve... Tenha sido ou não a PIDE (ou qualquer outro organismo do governo de Salazar) responsável pelo acontecimento em causa, tenha sido ou não esta morte um ato alheio a circunstâncias políticas, é inegável a importância documental de que se revestem textos como este de Jorge de Sena, e outros similares do Portugal Democrático, pelo que neles há de reflexo de um certo "estado de coisas" então vivido 
pelos portugueses. Poderão até ser considerados demagógicos. Pouco importa: "não há discurso político sem demagogia: boa demagogia ou má demagogia" - costumava dizer Sena, segundo depoimento de Mécia. A nós, leitores descompromissados com a busca da verdade histórica, interessa apreciar a magnífica página literária de primorosa retórica empenhada na conscientização político-ideológica e atestar seu valor enquanto construção discursiva eficiente, adequada a tempo e espaço precisos. Enfim, textos deste quilate fazem-nos compreender a importância de se ler o Portugal Democrático não apenas como fonte para o delinear da história recente do País. Há que lê-lo também, e com proveito, sob a ótica do literário.

A veiculação de notícias e comentários nesse teor só é possível graças à liberdade que gozavam no Brasil essa e outras publicações do gênero, quer em tempos de Juscelino Kubitschek de Oliveira, Jânio Quadros e João Goulart, quer mesmo durante a ditadura militar implantada a partir de 1964, que, ao contrário do previsível, respeitou a independência com que o jornal se firmara. Aliás, presente em cada número, o lembrete, emoldurado, "Portugal Democrático - um jornal português que não é submetido à censura" assegurava ao leitor uma credibilidade há muito ausente dos jornais publicados em Portugal, ou daqueles mantidos pela chamada "colônia" no Brasil, convictos reduplicadores da doutrina salazarista.

$\mathrm{Na}$ linguagem do jornal, como seria de esperar em publicações dessa natureza, não faltam interjeições, exclamações, repetições e certas “palavras de ordem”, certos "slogans", indispensáveis à proposta de envolver e influenciar o leitor - excelentes exemplos de uma retórica que mestre Jakobson localizou na "função conativa" da linguagem. Dentre outros, destaco o aforismo "Não se pode governar contra a vontade persistente de um povo" que se repete em alguns números, encimando um quadro de família: um homem de punho cerrado e erguido, uma mulher com uma criança ao colo e com a mão espalmada e o filho que exibe o letreiro "Vai-te Salazar". Esta imagem, com a legenda "O desenho que circula clandestinamente em Portugal", constitui-se como um clamor coletivo, uma espécie de "palavra de ordem" de efeito imediato.

Tentando configurar um perfil do noticiário, apontaria algumas constantes:

- a transcrição de notícias provenientes de múltiplas fontes, como a atestar uma busca de pluralidade, em que pese a ótica previsível de seleção das matérias;

- uma grande incidência de notícias sobre relações luso-brasileiras, onde aspectos diplomáticos ganham especial relevo;

- a reprodução de discursos em sessões solenes, dedicadas a datas portuguesas marcantes ou figuras oposicionistas; 
- os alentados dossiers em homenagem a vultos reverenciados pelos oposicionistas, como Jaime Cortesão ou Humberto Delgado;

- os artigos encadeados, seriais, que se estendem por vários números, estabelecendo um pacto de leitura. A série do "rato" (rato=Salazar), com textos de Jorge de Sena e desenhos/caricaturas de Fernando Lemos teve grande sucesso. Aliás, no que se refere a ilustrações, os traços de Fernando Lemos em muito contribuíram para levantar a qualidade gráfica, nem sempre brilhante, do jornal.

- a inclusão, desde o primeiro número e com certa freqüência, de poemas, assinados por nomes como Agostinho Neto, Carlos de Oliveira, José Gomes Ferreira, Sidônio Muralha, Alexandre O’Neill e outros. No número 29, de outubro de 59, há mesmo uma larga seleção de poemas que leva o título sintomático de "Uma frente de batalha chamada Poesia". E vale a pena frisar que é o recorte do poema de O' Neill aí estampado - "Perfilados de Medo" - que figura no dossier da PIDE dedicado ao autor, embora já tivesse sido editado sem qualquer problema em Portugal na Vértice (1952) e nos Cadernos do Meio-Dia (fev.1959). Evidencia-se, portanto, a atenção que a PIDE prestava ao Portugal Democrático ${ }^{4}$.

- as notícias de conferências, eventos e acontecimentos variados, de algum modo ligados às posições valorizadas pelo jornal;

- relevante é ainda a grande quantidade de notícias, ou documentos, censurados em Portugal que encontram acolhida, quando não grande destaque, neste jornal. Logo na primeira página do número 1, a chamada, com letras enormes, é para "As cartas proibidas de António Sérgio", dirigidas ao Ministro do Ultramar. No número 6, de 7 de dezembro de 1956, também na primeira página, a chamada é para o julgamento do "escritor e professor Dr. Óscar Lopes ${ }^{5}$ e demais 51 incriminados, acusados de actividades subversivas".

- por fim, sublinhando o caráter de sociabilidade e solidariedade que une o grupo ligado ao jornal, há que referir as campanhas de arrecadação de fundos, com propósitos político-filantrópicos: o "Natal do preso político", “donativos para custear as despesas de deslocação do delegado brasileiro à Europa no Movimento Pró-Anistia" (número 40, última página). Aliás, tratando da questão financeira, é preciso dizer que, não raro, os colaboradores do jornal não o eram apenas enquanto escritores... Não raro, além de contribuírem financeiramente para essas campanhas, cotizavam-se para fazer vir à luz mais uma tiragem do jornal...

Com o 25 de abril, o Portugal Democrático perde razão de ser. Ainda sobrevive até março de 1975 (n 204), mas o número 205, não datado e de feição gráfica diferenciada, dá por encerrada essa trajetória do memorável jornal. Jornal cujos propósitos 
hoje certamente parecerão quixotescos e inócuos aos olhos políticos mais pragmáticos, tendo em vista sua distância geográfica do epicentro salazarista e a reduzida eficácia dos métodos de ação escolhidos. Contudo, sob uma ótica apenas comprometida com o que se poderia chamar a "qualidade do texto", é inegável que este periódico se constituiu como um dos mais brilhantes que alguma assumida Oposição foi capaz de manter, por tanto tempo, em tão alto nível.

\section{$\operatorname{son} 2$}

\section{NOTAS}

1 Vale a pena ler na íntegra as notas com que Sena introduz o poema em suas diferentes publicações em jornais: vide SENA, [2000]: 255-261

2 Colóquio Internacional "Jorge de Sena e outros escritores portugueses num Brasil recente", que transcorreu de 25 a 27 de agosto de 1998 no Real Gabinete Português do Rio de Janeiro.

3 "oficial de ligação ao marechal Craveiro Lopes eprincipal organizador da intentona" segundo se lê em MATTOSO, José, org. História de Portugal. Lisboa:Estampa, s/d v.VII, p.537

4 Esta informação me foi prestada por Maria Antónia Oliveira, que prepara uma biografia do poeta.

5 No número 8, de 15 de fevereiro de 1957, com o título de "O Julgamento de Óscar Lopes", lê-se a seguinte nota.

Continuam a manifestar-se reações dos círculos intelectuais brasileiros contra a prisão do escritor e crítico português Óscar Lopes.

Depois da Associação Brasileira de Escritores (secção de São Paulo), da revista "Anhembi”, do jornal "O Estado de São Paulo", alguns intelectuais cariocas fazem sentir também o seu repúdio por mais esta arbitrariedade de Salazar.

Assim, os escritores Manuel Bandeira, Carlos Drummond de Andrade, Guilherme de Figueiredo, Cyro dos Anjos, Ledo Ivo, José Lins do Rêgo, entre outros, subscreveram uma declaração favorável ao crítico português. Essa declaração, sem caráter político, teve apenas como finalidade afirmar o apreço intelectual desses escritores, num belo gesto de solidariedade e de repúdio às perseguições por delitos intelectuais.

Portugal Democrático vê com júbilo que três décadas de propaganda salazarista não conseguiram convencer os intelectuais brasileiros das excelências do regime. Muito obrigado, portanto, àqueles que têm a coragem de saudar um escritor português que Salazar encarcerou.

\section{BIBLIOGRAFIA}

MATTOSO, José, org. (s/d) História de Portugal. Lisboa, Estampa, v. VII.

SANTOS. Gilda (1998) Da arte de ser multiplamente português num exílio brasileiro. In: JORGE DE

SENA vinte anos depois (2001), Lisboa, Cosmos/Câmara Municipal de Lisboa.

SENA, Jorge de. (1988). Estudos de Literatura Portuguesa-II, Lisboa, Ed. 70.

SENA, Jorge de. (2000). Fernando Pessoa \& C $C^{a}$ Heterónima, 3 ed., Lisboa, Ed. 70.

SENA, Mécia de \& SENA, Isabel Maria de, org. La scheda. In: STEGAGNO PICCHIO, Luciana, org. (1983),

Quaderni Portoghesi, Pisa: Giardini, 13/14: 14-22. 


\section{Resumo}

No capítulo das prefigurações do " 25 de Abril", o jornal Portugal Democrático (editado em São Paulo de 1956 a 1975) define-se como assumida forma de ação anti-salazarista no Brasil. Reunindo nomes de prestígio nas Letras, como Adolfo Casais Monteiro e Jorge de Sena, desempenha forte papel congregador dos exilados políticos, além de praticar vários modos de sociabilidade, em que se destaca o diálogo fértil com intelectuais brasileiros. A constância da poesia em suas páginas merece especial enfoque.

\section{Abstract}

On the chapter that prefigures the" 25 de abril ", the portuguese democratic newspaper (published in São Paulo since 1966 until 1976) defines itself as an anti- Salazar form of action in Brazil. Meeting names of prestige in humane letters, as Adolfo Casais Monteiro and Jorge de Sena, fulfills strong rôle that join together exiled politicians, farther on practice several manners of sociability which put in relief the fertile dialogue with brazilians intellectuals. The poetry constancy in their pages deserves a special center of interest.

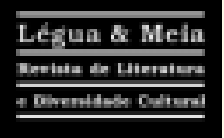

Lesua 8 Mela

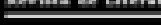
-
SANTOS, Gilda. O Jornal Portugal Democrático: Demandas do literário em meio à proposta política. Légua \&o meia: Revista de literatura e diversidade cultural. Feira de Santana: UEFS, v. 4, n 3 , 2005, p. 59-69.

Gilda Santos é Professora dos Cursos de Graduação e Pós-Graduação em Literatura Portuguesa na Fac. Letras da UFRJ, onde obteve seus títulos de Mestre e Doutor. Pós-Doutorado na University of California, Santa Bárbara. Regente da Cátedra Jorge de Sena para Estudos Literários Luso-Afro-Brasileiros/UFRJ e Coordenadora-Geral do Polo de Pesquisa sobre Relações Luso-Brasileiras no Real Gabinete Português de Leitura, onde também dirige a revista Convergência Lusíada. Organizadora de várias publicações, tem textos publicados no Brasil e no exterior. 